\title{
INTRODUCCIÓN / INTRODUCTION
}

\section{ALGUNAS APORTACIONES DEL ÁMBITO LATINOAMERICANO AL DERECHO INTERNACIONAL DE LOS DERECHOS HUMANOS, ESPECIALMENTE LOS DESCA}

\author{
SOME CONTRIBUTIONS FROM THE LATIN AMERICAN REGION \\ TO INTERNATIONAL HUMAN RIGHTS LAW, ESPECIALLY ESCR
}

\author{
Ruth Martinón Quintero* \\ Universidad de La Laguna
}

El 4 de julio de 2019 se celebró el Seminario «Los derechos económicos, sociales, culturales y medioambientales (DESCA) en la jurisprudencia de la Corte Interamericana de Derechos Humanos» dentro del Campus América 2019 de la Universidad de La Laguna. De los cuatro ponentes de ese Seminario, tres colaboran en este monográfico, que aspira a ser expresión de algunas contribuciones de América Latina al Derecho internacional de los derechos humanos, con estudios sobre el derecho a la vivienda, los derechos culturales de los pueblos indígenas y el derecho al medio ambiente como derecho autónomo. El cuarto artículo versa sobre un análisis de los tratados de inversión y los derechos humanos en América Latina.

Para comprender la relevancia de estas aportaciones es importante tener en cuenta la posición que han ocupado los derechos económicos, sociales y culturales (DESC) $)^{1}$ tanto como derechos fundamentales constitucionales como formando parte del Derecho internacional de los derechos humanos. En ambos ámbitos, ha predominado la dificultad de su consideración en plano de igualdad con los derechos civiles y políticos, especialmente en lo concerniente a su justiciabilidad ${ }^{2}$.

* Doctora por la Universidad Carlos III de Madrid, es licenciada en Derecho por la UNED y en Ciencia política por la Universidad Complutense de Madrid. Actualmente, es profesora contratada doctora de Derecho internacional público y Relaciones internacionales y directora académica del Centro de Documentación Europea de la Universidad de La Laguna.

${ }^{1}$ Se ha pasado a hablar de los DESCA en lugar de los DESC por la incorporación más reciente de los derechos ambientales.

2 Respecto a la justiciabilidad de los DESCA ante la Corte Interamericana de Derechos Humanos, véanse en especial los capítulos de M.Y. Robles Garza y E. Ferrer Mac-Gregor en L.E.

DOI: https://doi.org/10.25145/j.anfade.2020.37.01

Anales de la Facultad De Derecho, 37; septiembre 2020, pp. 9-13; ISSN: e-2530-8319 
En el ámbito internacional, aunque la Declaración Universal de Derechos Humanos de 1948 abarcó todos los derechos de forma conjunta, la tensión política de la guerra fría hizo que la distinción se reflejara de manera rotunda en la aprobación por parte de la Asamblea General de Naciones Unidas, en 1966, de dos tratados diferentes: uno, el Pacto Internacional sobre Derechos Civiles y Políticos; y, otro, el Pacto Internacional sobre Derechos Económicos, Sociales y Culturales.

Esta concepción se trasladó también a los sistemas regionales de protección de derechos humanos, no solo por la división de los diferentes tipos de derechos en convenios distintos, sino porque los derechos civiles y políticos gozan de un sistema de protección más amplio y perfeccionado. Lo observamos en el caso del Consejo de Europa, y también en el Sistema Interamericano de Derechos Humanos (SIDH), aunque en ambos existen o se han desarrollado resquicios que posibilitan su justiciabilidad por el Tribunal Europeo de Derechos Humanos y por la Corte Interamericana de Derechos Humanos.

Ciertamente, en Occidente, la evolución del principio de igualdad y no discriminación no produjo un verdadero cuestionamiento de las relaciones sociales fruto del sistema económico hasta la aparición de la concepción del Estado social de Derecho, en la que 'social' hace referencia a la «corrección del individualismo clásico liberal a través de una afirmación de los llamados derechos sociales y de una realización de objetivos de justicia social»; en el cual, continúa el profesor Elías Días, el propósito es "compatibilizar en un mismo sistema dos elementos: uno, el capitalismo como forma de producción, y otro, la consecución de un bienestar social general $»^{3}$. Así, mientras los derechos civiles y políticos se atribuyen a la persona abstracta, los derechos económicos, sociales y culturales se configuran más como los derechos de la persona en su especificidad social.

Por ello, «los derechos sociales se configuran como derechos de igualdad entendida en el sentido de igualdad material o sustancial, esto es, como derechos, no a defenderse ante cualquier discriminación normativa, sino a gozar de un régimen jurídico diferenciado o desigual en atención precisamente a una desigualdad de hecho que trata de ser limitada o superada $»^{4}$.

Sin embargo, la dificultad de la compatibilización a la que hace referencia el profesor Elías Díaz abocó a la asunción implícita de la imposibilidad de incorporar todas las implicaciones jurídico-políticas del Estado social y a la concepción predominante de los DESC como derechos secundarios. De este modo, estos se han visto «limitados o postergados como consecuencia de la incidencia ideológica y fáctica

Ríos Vega e I. Spigno (dirs.), Los derechos fundamentales en el siglo XXI, tomo VI. Los derechos sociales, económicos, culturales y ambientales, Tirant lo Blanch, Ciudad de México, 2018.

3 Díaz, E., Estado de Derechos y sociedad democrática, Taurus, Madrid, 1986, pp. 84 y 92.

${ }^{4}$ Prieto SAnchís, L., "Los derechos sociales y el principio de igualdad sustantiva», Revista del Centro de Estudios Constitucionales, 22, 1995, pp. 9-57, p. 16. 
del mercado sobre la política y el derecho"s; calificados como derechos prestacionales que debían quedar «limitados a principios programáticos y cumpliendo su función como criterios de interpretativos que imponen al legislador su desarrollo, concreción y gradación ${ }^{6}$. Porque incluso cuando los derechos sociales pueden implicar una superación del inicial individualismo jurídico, especialmente en los derechos que son conquistas del movimiento obrero ${ }^{7}$, no logran subvertir la concepción individual del Derecho y de los derechos heredera de la concepción liberal que hace a cada persona dueña de sus propios actos sin atender al contexto, a los grupos sociales y a la relación de poder entre ellos.

Cuando admitimos que pese al reconocimiento y la garantía jurídicos de los derechos humanos hay grupos que por razones sociales no pueden gozar de los mismos o, al menos, no en condiciones de igualdad respecto al resto de grupos, y la pertenencia a dicho grupo no es voluntaria pero sí determina el abanico de acciones posibles del individuo, no estamos ante una discriminación que, en principio, pueda ser resuelta con el conocimiento individual de los casos que puedan llegar al sistema judicial. Es más, con frecuencia se trata de violaciones de derechos que resultan difíciles de individualizar en conductas discriminatorias determinadas porque se enmarcan en prácticas sociales amplias y difusas, no necesariamente intencionadas, por las que un grupo social se encuentra en una posición estructural, sistémica, de subordinación respecto al resto de grupos sociales.

En el ámbito del Derecho internacional, la respuesta a estos problemas se concretó en la reivindicación de la interdependencia e indivisibilidad de los derechos humanos, proclamada con rotundidad en la Conferencia sobre Derechos Humanos de Naciones Unidas de 1993: «Todos los derechos humanos son universales, indivisibles e interdependientes y están relacionados entre sí. La comunidad internacional debe tratar los derechos humanos en forma global y de manera justa y equitativa, en pie de igualdad y dándoles a todos el mismo peso» ${ }^{8}$. Esta concepción encuentra su fundamento en el basamento axiológico de todos los derechos: el principio de igualdad y dignidad de todos los seres humanos. Este, en el ámbito interno, se concreta en una concepción del Estado de Derecho como «método político-jurídico encaminado a lograr el respeto y la garantía de los derechos fundamentales del hombre, y, paralelamente, la más plena realización de las dimensiones de racionalidad y libertad real y material en que debe basarse progresivamente la convivencia humana». En esta concepción, los derechos sociales «no solo con compatibles con

5 Añón, M.J., «Derechos sociales: inconsistencia de una visión compartimentada», en Teoría de la Justicia y derechos fundamentales. Estudios en homenaje al profesor Gregorio Peces-Barba, volumen III, Dykinson, Madrid, 2008, pp. 21-46, p. 46.

${ }^{6}$ AÑón, M.J., op. cit., p. 38.

7 Barcellona, P., «Los sujetos y las normas», en Oliva, E., Problemas de legitimidad del Estado social, Trotta, Madrid, 1991, pp. 29-47, p. 33.

${ }^{8}$ Declaración y Programa de Acción de Viena, adoptado por la Conferencia Internacional sobre Derechos Humanos en Viena el 25 de junio de 1993, punto quinto.

9 DíAz, E., op. cit., p. 66. 
la democracia, sino que son un componente esencial de los valores fundamentales de la misma, no habiendo razones de peso para su postergación o falta de consideración como tales» ${ }^{10}$.

Vale la pena detenerse en la dignidad humana como fundamento de este proceso porque con independencia de la polémica de su estatus jurídico ha servido en diversos ámbitos de protección de derechos humanos para fundamentar «manifestaciones de derechos y estándares de protección que no cuelgan de derechos fundamentales positivados como tales»; por ejemplo, el derecho a un mínimo vital o existencial, o el derecho a un trato digno, especialmente, a los grupos vulnerables ${ }^{11}$.

Es en este marco general en el que encontramos las aportaciones que se recogen en este número de la revista Anales de la Facultad de Derecho. Todas ellas son aportaciones muy interesantes y abordan aspectos innovadores en el Derecho internacional de los derechos humanos.

El trabajo de la profesora Robles Garza comienza presentando el concepto de vivienda en el Derecho internacional de derechos humanos en general y en el SIDH en particular. Expone la falta de consenso sobre la aplicación directa del artículo 26 de la Convención Americana sobre Derechos Humanos $(\mathrm{CADH})^{12}$, que permite proteger los DESCA como derechos autónomos. Si bien el derecho a la vivienda nunca ha sido protegido directamente por esa vía, sino a través del mecanismo de la conexión con otros derechos. A continuación se expone la amplia jurisprudencia de la Corte IDH en la que se encuentra ese razonamiento jurídico, protegiendo el derecho a la vivienda por conexión con el derecho a la propiedad privada, el derecho a la circulación o al movimiento o el derecho a la libertad personal. Se detiene en denunciar cómo no se han cumplido la mayor parte de medidas reparadoras en materia de vivienda de esas sentencias y finaliza reivindicando sobre una amplia argumentación jurídica la justiciabilidad directa y autónoma del derecho a la vivienda a partir del artículo 26 de la CADH.

Las pecularidades de los pueblos indígenas están en el origen de algunas particularidades muy interesantes de la labor pretoriana de la Corte IDH. El profesor Gajardo Falcón se centra en la jurisprudencia de este tribunal internacional de los derechos humanos sobre los derechos culturales de estos pueblos. Presenta una sistematización de esas sentencias en función de los derechos de la CADH (derecho a la vida, derecho a las garantías judiciales, derecho a la propiedad, derecho a

10 AnNón, M. J., op. cit., p. 40.

11 Caballero Sánchez, R., "La dignidad humana como fuente atributiva de derechos fundamentales no formalizados» (2017), en Puyol Montero, José María (coord.), Studies on life, human dignity and law. Dignidad humana, vida y derecho, Tirant lo Blanch, Valencia, pp. 25-61, p. 30.

12 Artículo 26 CADH: Artículo 26. Desarrollo Progresivo. Los Estados Partes se comprometen a adoptar providencias, tanto a nivel interno como mediante la cooperación internacional, especialmente económica y técnica, para lograr progresivamente la plena efectividad de los derechos que se derivan de las normas económicas, sociales y sobre educación, ciencia y cultura, contenidas en la Carta de la Organización de los Estados Americanos, reformada por el Protocolo de Buenos Aires, en la medida de los recursos disponibles, por vía legislativa u otros medios apropiados. 
la familia y derechos de la niñez, derecho a libertad de pensamiento y de expresión) a los que se vinculan los derechos culturales. Esto, a su vez, muestra la incidencia de la cultura de los pueblos indígenas en la interpretación de esos derechos en estos casos marcados por la multiculturalidad. Sin embargo, se plantea que en el futuro es posible que se pongan de manifiesto los límites de la adaptación de los derechos a las culturas de los pueblos indígenas cuando estas atenten contra el núcleo de los derechos de la $\mathrm{CADH}$ o su protección pueda implicar la vulneración de los derechos humanos de terceros.

Digno J. Montalbán Zambrano presenta una innovación muy reciente de la Corte IDH respecto al derecho al medio ambiente sano. Durante años, este fue introducido en su jurisprudencia a través de la conexión con la vulneración de derechos civiles y políticos. En una opinión consultiva de 2017, primero, y en una sentencia de 2020, después, se admitió un derecho al medio ambiente sano autónomo, que supone la protección de la naturaleza en sí misma, sin necesidad de vincular los atentados contra ella con dańos o riesgos en las personas. El artículo explica la aproximación ecocéntrica que este planteamiento supone y la compara tanto con el antropocentrismo clásico predominante hasta ahora como con la corriente biocéntrica. El autor defiende que este cambio en los fundamentos filosóficos últimos del Derecho de los derechos humanos no constituye un debilitamiento del mismo, sino la puerta a una interpretación holística en la que se protege a la naturaleza como «inherente al ser humano no como su piloto sino como un pasajero más».

El último artículo de este monográfico lo escribe Lucas Sebastián de Erice Aranda. Aborda cómo los tratados bilaterales de inversión (TBI) pueden afectar por sus propias características y contenido estándar al respeto de los derechos humanos, primordialmente los DESCA. En especial, el autor se detiene en mostrar cómo los TBI de vieja generación generan puntos de fricción con la capacidad regulatoria del Estado en materia de derechos humanos. Se explican tres posiciones tipo de Estados latinoamericanos: la de México, que ha decidido continuar con los TBI; la de Ecuador, que ha rechazado este tipo de tratados pero sin que esté clara su posición de futuro; y la de Brasil, que nunca firmó un TBI y actualmente promueve los acuerdos de cooperación y facilitación de inversiones, en los que desaparecen las cláusulas y mecanismos más lesivos para los derechos humanos. Se defiende que en la medida en que este modelo de tratados sirve para alcanzar el objetivo de canalizar la inversión extranjera, continuar en la actualidad con los TBI tradicionales supone una decisión voluntaria y consciente por parte del Estado de limitar en gran medida su capacidad para cumplir sus obligaciones internacionales en materia de derechos humanos. 
